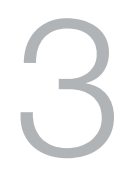

\title{
Diasporic looking: Portraiture, diaspora and subjectivity
}

\section{Gali Weiss}

How does an understanding of diaspora contribute to the way we think about and respond to the world around us? For a number of scholars, diaspora is one of the most relevant social formations for framing the way we understand our times. Some even propose that diaspora is the only social formation that enables cultural identity to survive in a globalised world, describing 'diasporised' identity as one that can hold together seemingly contradictory positions. ${ }^{1}$ Diaspora discourse and theorisation offer a critical space for thinking about the mass movements of people that defined the twentieth century and continue to shape the twenty-first. ${ }^{2}$ More significantly for this essay, that space is also one in which we can explore how diasporic experience influences the way we view, articulate and aestheticise ourselves and the contemporary world.

\footnotetext{
1 In relation to contradictory positions of identity, Daniel Boyarin and Jonathan Boyarin write of 'an Egyptian Arab who happens to be Jewish, and a Jew who happens to be an Egyptian Arab'. Relating to gender, they argue that 'rather than the dualism of gendered bodies and universal souls ... - the dualism that the Western tradition offers - we can substitute ... bodies that are sometimes gendered and sometimes not. It is this idea that we are calling diasporized identity'. See Daniel Boyarin and Jonathan Boyarin, 'Diaspora: Generation and the ground of Jewish diaspora', in Jana Evans Braziel and Anita Mannur (eds), Theorizing diaspora, London, Blackwell Publishing, 2003, p. 109.

2 Braziel and Mannur, 2003, p. 3.
} 
Representations of 'face', fluidity of gesture and form, notions of presence and absence, self and other, the real and the imagined; such themes, which relate to conceptual, philosophical and material expressions of 'being', have always been part of my art-making. It was only as I embarked on practice-based academic research that I identified this practice in terms of portraiture. Simultaneously, I came to understand the significance of diasporic experience for my artistic vision, a vision emerging from a family history of migration, closely held cultural and spiritual values, and identification as IsraeliAustralian. While the idea of diaspora has evolved and changed considerably in recent decades, ${ }^{3}$ what continues to be recognised as common to all diasporic communities is an emotional allegiance to the 'old homeland'. Most critical attempts at characterising diaspora refer, whether explicitly or by implication, to a centre or home of origin - historic, current or imaginary. ${ }^{4}$ The connection to a home other than where one is situated, and thereby the promise or possibility of a return or quest for a return of sorts, lies at the heart of diasporic consciousness. Diasporic identity at once belongs and does not belong to both the home of origin and the adopted home. Diasporic consciousness involves a sense of difference and multiplicity of belonging, a sense of 'otherness', and hence of displacement. The identity of the displaced is not 'complete' as a distinct, fixed identity but, in the words of Zygmunt Bauman, is 'wholly or in part "out of place" everywhere, not ... completely anywhere ... nowhere will one be fully "at home"'. ${ }^{5}$ Diaspora can in itself, however, be viewed as a particular space of belonging, in which, as Stuart Hall claims, 'diaspora identities are constantly producing and reproducing themselves anew, through transformations and difference' ${ }^{6}$ For Hall, the future existence of diaspora identity is in its continual re-creativity, re-being; that is,

3 According to Braziel and Mannur, theories of diaspora 'have emerged in area studies, ethnic studies, and cultural studies as a major site of contestation. Since the journal Diaspora: A Journal of Transnational Studies was inaugurated in 1991, debates over the theoretical, cultural, and historical resonances of the term have proliferated in academic journals devoted to ethnic, national, and (trans)national concerns'. See Braziel and Mannur, 'Nation, migration, globalization: Points of contention in diaspora studies', in Braziel and Mannur, 2003, p. 2.

4 Robin Cohen, Global diasporas: An introduction, London, University College London Press, 1997, p. 2.

5 Zygmunt Bauman, Identity: Conversations with Benedetto Vecchi, Cambridge, Polity Press, 2004, pp. 13-14.

6 Stuart Hall, 'Cultural identity and diaspora', in Braziel and Mannur, 2003, p. 244. 
in its' 'becoming'. It is with these ideas, this particular conjunction of absence and presence, of belonging and not belonging, that I wrestle in making portraits, and which I explore in this essay.

\section{Diaspora as a way of viewing the world}

Diaspora - the diaspora as I knew it - was a familiar term that referred specifically to the extensive history of the Jewish people. Until only a few decades ago, diaspora was likely to refer to the dispersion of Jews from their original homeland over 2,000 years ago; although sometimes also to the centuries-old dispersion of Armenians from their original and then fragmented homeland. Since the late 1960s, dispersed communities once described as exile groups, overseas communities, ethnic and racial minorities and so on have been re-identified in the terms of diaspora. ${ }^{7}$ The complexity of diaspora is evident not only in the range of definitions that are currently in circulation but in the variety of diaspora now identified and the variables within each of these.

My family history demonstrates this: my parents were part of the Jewish diaspora in Eastern Europe in their respective countries of birth before 'returning' to their biblical homeland in Israel, at that time Palestine. When I was a child my parents migrated again, this time with family, to Australia, where we were active in the Jewish community and identified as Israelis living in Australia. As a young adult I returned to live in Israel, then returned after 14 years to live again in Australia. This history of attachment to Israel is so embedded in my family identification that I once heard my Australian-born daughter, when asked by a new acquaintance where she 'came from', answer, 'Israel'. My family has continuously moved backwards and forwards between places, real and imaginary, experiencing the paradox 'of and between location and dislocation' that is a common dimension of diasporic positioning. ${ }^{8}$

$7 \quad$ Khachig Tölölyan, 'Rethinking diaspora(s): Stateless power in the transnational moment', Diaspora, vol. 5, no. 1, 1996, p. 3.

8 Avtar Brah, Cartographies of diaspora: Contesting identities, London and New York, Routledge, 1996, p. 204. 
Avtar Brah proposes a viewing of diaspora through a 'politics of identification' as opposed to a 'politics of identity', accommodating the different identities people inhabit that interweave relations of race, gender, class and sexuality. ${ }^{9}$ If we accept an idea of diaspora that goes beyond definitions of particular minorities, then how are notions of diaspora placed and enacted within creative production? How do we use the 'language' of diaspora and its inherent ambiguities to both 'read' and depict notions of identity?

Diaspora, and particularly the profusion of diaspora and diasporic identity in the past few decades, has affected both metaphorically and materially the way in which we understand notions of identity, individualism, boundaries and so forth. With this in mind, we can speak of the role of artistic practice not so much in terms of reflecting who we are but as a performative mode of agency that engages us in a positioning or negotiating of a form of subjectivity.

Ernst van Alphen claims that art can act as agency for cultural discourse; it has the power to transform the ways in which cultural issues are conceptualised, as well as represented..$^{10}$ Art practice not only reflects culture and philosophy, it provides us with a way of understanding, such that art can be viewed as 'a mode of thinking'. ${ }^{11}$ We can see, then, that both diaspora and art can be viewed as frames for undertaking cultural studies and philosophy, not only as historical products.

As already noted, what is constant within diasporic consciousness is the existence of a relationship with a homeland and thereby a continuity of belonging or reference. It is this relationship, this inescapable link to a history, that is at work in my approach to portraiture. More precisely, my practice is driven by an urge to maintain some form of connection, imaginary or actual, with a past (of the genre - that is, its history - and of the portrait's reference) while exploring new meanings and possible futures.

9 Brah, 1996, p. 93.

10 Ernst van Alphen, Art in mind: How contemporary images shape thought, Chicago, University of Chicago Press, 2005, p. xiii.

11 van Alphen, 2005, p. xv. 
As I explore below, crafting notions of identity and representation through diasporic consciousness opens a distinctive way of viewing and experiencing art. In the case of the contemporary portrait, such a view is attentive to the ambiguities inherent in both diaspora and portraiture: the tensions between stillness and fluidity, stability and movement, belonging and displacement, difference and sameness, presence and absence, being one and multiple.

\section{Diasporic visual culture}

Through the final decades of the twentieth century, the visual arts were being 'disentangled' from their traditional forms such as painting and sculpture and repositioned not only within fine arts but within a broader visual culture, thus foregrounding a new discourse on the nature of contemporary visuality itself. ${ }^{12}$ Diasporic visual culture is an area emerging within visual culture studies, giving special focus to the visual representation of diasporic experience and identity. Nicholas Mirzoeff recognises the paradoxes involved in attempting to represent diaspora, since by its nature contemporary diaspora cannot be fully known, seen or quantified: 'A diaspora ... cannot be represented from the viewpoint of one-point perspective. ${ }^{\prime 3}$ The space of diaspora exists in multiple times and places, encompassing those who leave as well as those who stay and those who return. It is multiple, fluid, and at times paradoxical. It is about the future as well as the past. While diasporic identity can be understood in terms of 'double consciousness' as a tension in belonging, or as Mirzoeff claims, as a dialectic between past and present, it may also be rethought in terms of an indeterminate future to come. ${ }^{14}$

Just as concepts and terms of identity are continuously evolving, so too are the terms of portraiture. Portraiture in western art is a genre whose credibility in art-historical terms traditionally depended on notions of authenticity. The conventions of portraiture claim referentiality as the element that differentiates the portrait from all other artistic genres. ${ }^{15}$

12 Barbara Kirshenblatt-Gimblett and Jonathan Karp (eds), The art of being Jewish in modern times, Philadelphia, University of Pennsylvania Press, 2008, p. 1.

13 Nicholas Mirzoeff (ed.), Diaspora and visual culture: Representing Africans and Jews, London and New York, Routledge, 2000, p. 2.

14 Mirzoeff, 2000, p. 4.

15 Richard Brilliant, Portraiture, Cambridge, MA, Harvard University Press, 1991, pp. 7-8. 
Informing the traditional portrait is its indexical relationship to a particular individual outside the picture. Contemporary discussions of the terms of portraiture, however, range from echoing these older ways of thinking to new conceptualisations that challenge the genre's conventions of presence and authenticity.

\section{Visualising the copy as a tool for new thinking}

Susan Buck-Morss has argued that what is powerful in a photograph or digital image is not its ability to re-present but its ability to generate meaning. As previously suggested, the authenticity of the image as art-object may matter in terms of art history (as the product or reflection of a historical period or person), but within visual studies the reproduction takes on meaning in new ways beyond the idea of origin: 'The image disconnects from the idea of being a reproduction of an authentic original, and becomes something else. ${ }^{\prime 6}$ Buck-Morss calls reproduced images, specifically as produced by digital technology, 'tools of thought' that mediate between things and thinking. ${ }^{17}$

Perhaps this is the approach taken by Hélène Cixous when she writes of Roni Horn's photographic portraits: 'These are not photographs, these are portraits of looks that don't allow themselves to be taken, snapshots of instants, series of winks of an eye. ${ }^{18}$ Horn's photographic portraits, despite the repeated imagery of the individual photographed, do not represent that individual, claims Cixous. In her Portrait of an image 2005: Isabelle Huppert impersonating herself in her film, ${ }^{19}$ the viewing position is a face-to-face engagement with the image of a face. As the title implies, the artist's intention does not seem to be to depict the 'real' Isabelle Huppert. Cixous explains how this series challenges the referential purpose of the portrait:

16 Susan Buck-Morss, 'Visual studies and global imagination', Papers of Surrealism, Issue 2, Summer, 1991, p. 23.

17 Buck-Morss, 1991, p. 20.

18 Hélène Cixous, 'A kind of you: 6 portraits by Roni Horn', catalogue, ACCA, Melbourne, 2007, p. 8 (from her 'Portraits of portraits: The very day/light of Roni Horn', in Cixous, Poetry in painting: Writings on contemporary arts and aesthetics, ed. Marta Segarra and Joana Masó, Edinburgh, Edinburgh University Press).

19 Cixous, 2007, p. 64. For an image of this portrait in part, see www.hauserwirth.com/artists/ images-clips-view//?artist_id=14\&a=roni-horn\&p=66, accessed 2 January 2014. 
[it] deconstructs the entire traditional unthinking approach to the thing called Portrait, the use made of the word Portrait, when it is referred to people. For this to happen the Portrait must personify the image. The difference between an image and a face: the face sees you. The image does not see you. Is seen. The gaze of the Portraitist gives a figure to the image. ${ }^{20}$

The image alone is not the portrait, and the person the image relates to provides only a fragment of the subject. As Didier Maleuvre argues in this volume, it is the artist's gaze that creates the possibility of the image becoming a face, which as a consequence engages the viewer so that they might discover the 'pearl' that is the portrait. The portrait is a matter of relationality.

\section{The image, the copy}

Can a photograph, or reproduction, in itself provide evidence of the 'realness' of an original? The digital age has shown us that the filmed or photographic image can be manipulated, that virtual images can be created, referring not to a real existence outside the image but to the idea of a reality.

How can authenticity remain a value in a medium that centres on reproduction, especially when reproduced images are copied, repeated and layered? It would appear that continued reproducibility distances the viewer from an origin and thereby creates a sense of loss of truth, truth being a notion often aligned with origin.

The use of repetition has been central in the work of ChineseAustralian artist Lindy Lee-from her 1980s works using photocopied Renaissance portraits, to her current work in which she draws directly on personal history and family ancestry. Many of Lee's works from the 1990s incorporate repeated images of photocopies of European Old Master portraits into grid or linear formations, playing with differing degrees of visibility and variations in colour tone. This work was informed by Lee's consciousness of her diasporic identity, using the copy as a metaphor for 'unbelonging' or cultural displacement. Lee was

20 I have reproduced this and subsequent quotes from Cixous as they appeared in the ACCA catalogue 'A kind of you: 6 portraits by Roni Horn', with the understanding that the visual representation of the text, including grammatical omissions, are congruent with Cixous' meaning. Cixous, 2007, pp. 12-13. 
born in Australia of Chinese heritage. She has stated, 'I had always felt a fraud - a copy, and a flawed one at that ... I was counterfeit white and a counterfeit Chinese'. ${ }^{21}$

In An ocean of bright clouds, an ocean of solemn clouds (1995) (Figure 3.1), Lee uses 25 photocopies of a single image in varying degrees of exposure so that the face in the work appears and disappears in tone and form but is decipherable through repetition. Significantly, the repetition of the face does not enhance its visibility or particularity, but rather reduces it to anonymity. Rather than a portrait of a fully present individual, Lee creates a heightened sense of the tension between presence and absence.

Melissa Chiu points out that in adopting the copy as a methodology, Lee is attempting to locate herself within the western art-historical canon, at the same time as disrupting that tradition by transforming the notion of the original into the anonymous and reproducible. Lee's use of repetition in the different versions of the original on each panel is not structured as a progression or narrative but as an entity. Here repetition is used to suggest how identity differs according to time and context in 'a state characterised by moments of flux and uncertainty' ${ }^{22}$

Edward Colless suggests that viewing Lee's 1990s portraits from the position of cultural tradition has the effect of casting Australian culture as a version or 'copy' of European culture. Colless views these portraits, which simultaneously obscure and delineate the face, as metaphors for displaced cultural memory:

These plaintive ghosts from an Old World hang forever at both a temporal and geographical distance from us. Looking at Lee's appropriated portraits we lose and partially recover images from the past, but images of a cultural tradition that was never really our own. Perhaps we are condemned to see them this way-those original works of art - as remote and speechless icons, because we are their false descendants. Just as the artist considers herself a false descendant of European art, producing false copies of that art as her own. ${ }^{23}$

21 Melissa Chiu, 'Struggling in the ocean of Yes and No', in Benjamin Genocchio and Melissa Chiu, Lindy Lee, Sydney, Craftsman House, 2001, p. 16.

22 Chiu, 2001, p. 16.

23 Edward Colless, 'Lindy Lee: The many faces of Lindy Lee', Artcollector, Issue 26, October, 2003, www.artcollector.net.au/LindyLeeTheManyFacesofLindyLee, accessed 2 January 2014. 


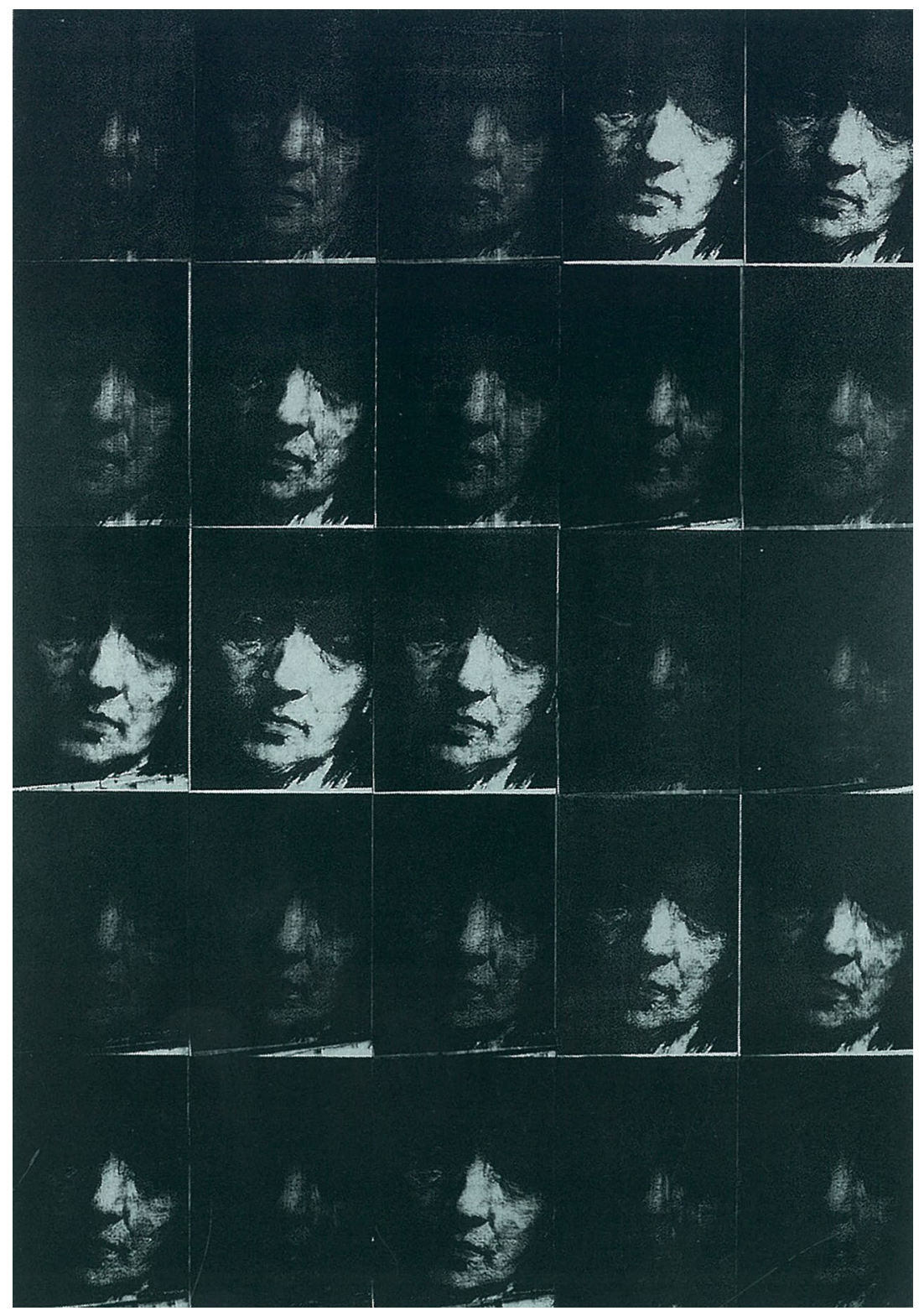

Figure 3.1: An ocean of bright clouds, an ocean of solemn clouds, Lindy Lee, 1995, photocopy and acrylic on board, $205 \times 143 \mathrm{~cm}$.

Source: Courtesy of the artist and Roslyn Oxley9 Gallery, Sydney. 


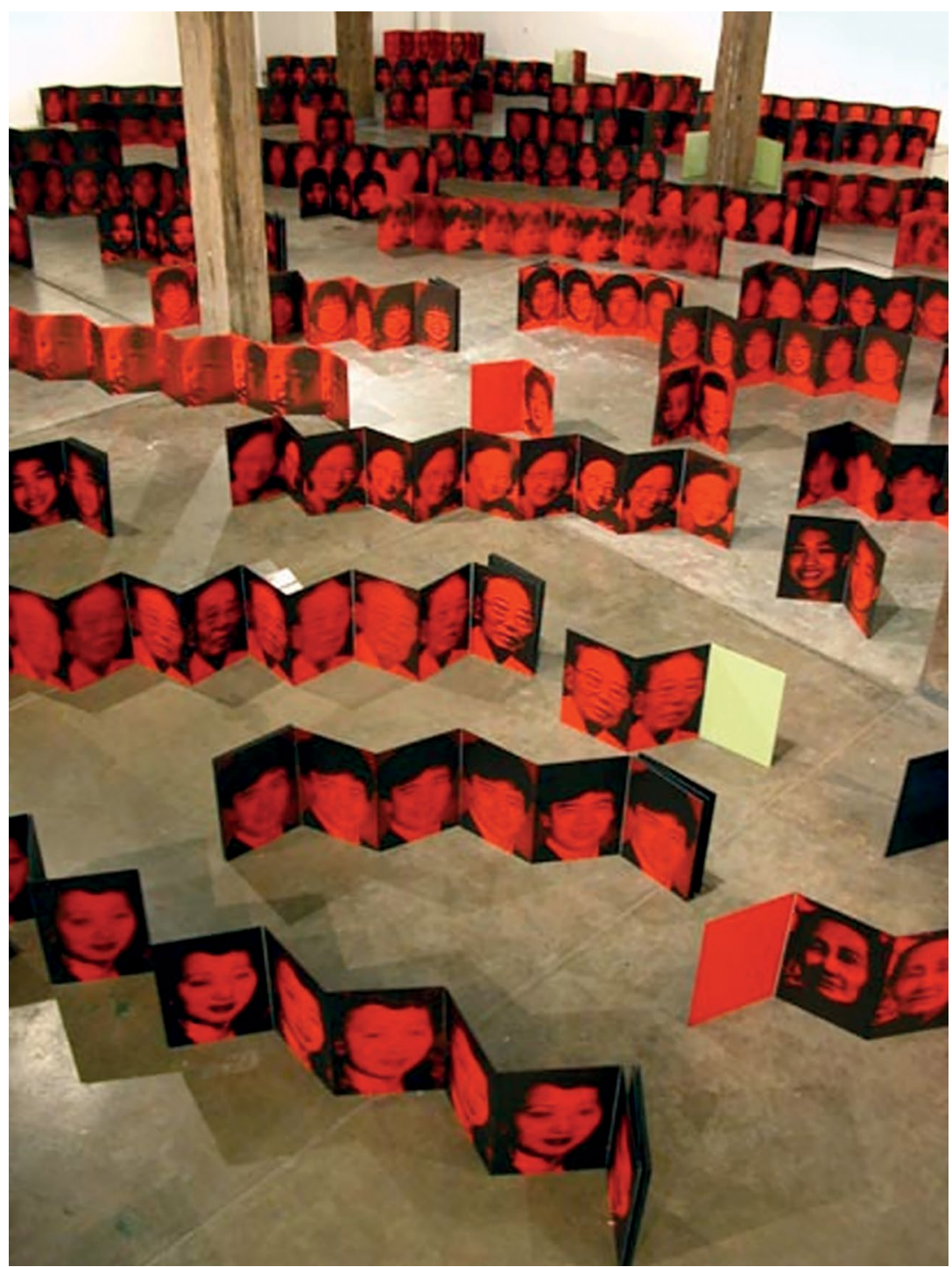

Figure 3.2: Birth \& death, Lindy Lee, 2003, Installation Artspace, Sydney, inkjet print and acrylic on Chinese accordion books, installation dimensions variable.

Source: Courtesy of the artist and Roslyn Oxley9 Gallery, Sydney.

A copy, however, as Colless notes, can only be regarded as 'false' or 'bad' when it is compared to the original. Lee's art produces a new sense of original by deviating from what it has copied while nevertheless relating to that original as the basis of its being. While these works 
could be claimed to be self-portraits of sorts, relating to cultural memory and artistic ancestry, Lee has in recent years turned to more direct forms of personal history and family ancestry. ${ }^{24}$

Her 2003 installation Birth \& death ${ }^{25}$ (Figure 3.2) comprises one hundred concertina books of eighteen panels of family-album images of enlarged faces that journey across the floor of the gallery space. The gallery becomes inhabited with Lee's Chinese family, past and present, alive and deceased, in stillness and in movement. The installation is at once a collective portrait and a self-portrait, a family genealogy and a moment in time.

\section{Familial looks and postmemory}

Family photographs are likewise central to Marianne Hirsch's study of postmemory. Postmemory, explains Hirsch, is a particular way of relating to the past through imaginative investment and creation. It 'characterises the experiences of those who grow up dominated by narratives that preceded their birth, whose own belated stories are evacuated by the stories of the previous generation shaped by traumatic events that can be neither understood nor recreated' ${ }^{26}$ The photograph, in particular the family-album photograph, whose images and narratives extend well into subsequent generations, facilitates this transference. Such a photograph can be read as trace; the trace of the photographed person or place; an 'outline' trace of their materiality; and as the trace of a time that no longer exists. This photograph signifies both life and death, for it shows evidence of the object that was photographed and at the same time we recognise the sense of the 'having-been-there' that creates a sense of loss in the viewing ${ }^{27}$ This photograph both blocks memory, because it is not reviving experience, and attests to its past reality. ${ }^{28}$ The function of the photograph as postmemory is as a site that mediates between past and present.

25 Roslyn Oxley9 Gallery, Lindy Lee-Birth \& death-Roslyn Oxley9 Gallery, 2013, www. roslynoxley9.com.au/artists/20/Lindy_Lee/471/38857/, accessed 2 January 2014.

26 Marianne Hirsch, Family frames: Photography, narrative and postmemory, Cambridge, MA, Harvard University Press, 1997, p. 22.

27 Hirsch, 1997, p. 20.

28 Hirsch, 1997, p. 82. 
Hirsch has developed the notion of postmemory in relation to Holocaust survivors, but considers it useful in describing the process at work in the continuity of collective memory in diasporic situations. The idea that memory has both public and private dimensions is integral to the diasporic vision, for this dual status shapes and marks it. This shared memory forms the basis of the traditions and practices of diasporic communities, and the basis of their existence. Without the shared memory of the home of origin and of a collective if diverse past, even if mythologised or abstract, diaspora would not exist. According to Hirsch, the inheritance of history as postmemory distinguishes it from memory as recollection, 'by generational distance, and from history by deep personal connection'. Photographs can connect firstand second-generation remembrance, memory and postmemory, for they represent what has been and what no longer is, but also what continues to be from the position of those who do the viewing. ${ }^{29}$

What is particularly meaningful in family photographs is the performative function of the 'affiliative' gaze, a term that Hirsch uses to argue that there is a particular kind of viewing identification in relation to the familial image:

Recognizing an image as familial elicits ... a specific kind of readerly or spectatorial look, an affiliative look through which we are sutured into the image and through which we adopt the image into our own familial narrative. Akin to Barthes's move from the studium to the punctum, it is idiosyncratic, untheorizable: it is what moves us because of our memories and our histories, and because of the ways in which we structure our own sense of particularity. ${ }^{30}$

The affiliative look is not a gaze that is restricted to 'knowledge' of or about the subject but one in which identification follows the particular intimacy of a familial look or exchange of looks. The affiliative look is characterised by its collective sense of intimacy and familiarity. It is the search for this kind of intimate acknowledgement of experience rather than recognition of identity that guides the artistic choices I make in producing portraits.

29 Hirsch, 1997, pp. 22-3.

30 Hirsch, 1997, p. 93. 


\section{The practice of portrayal}

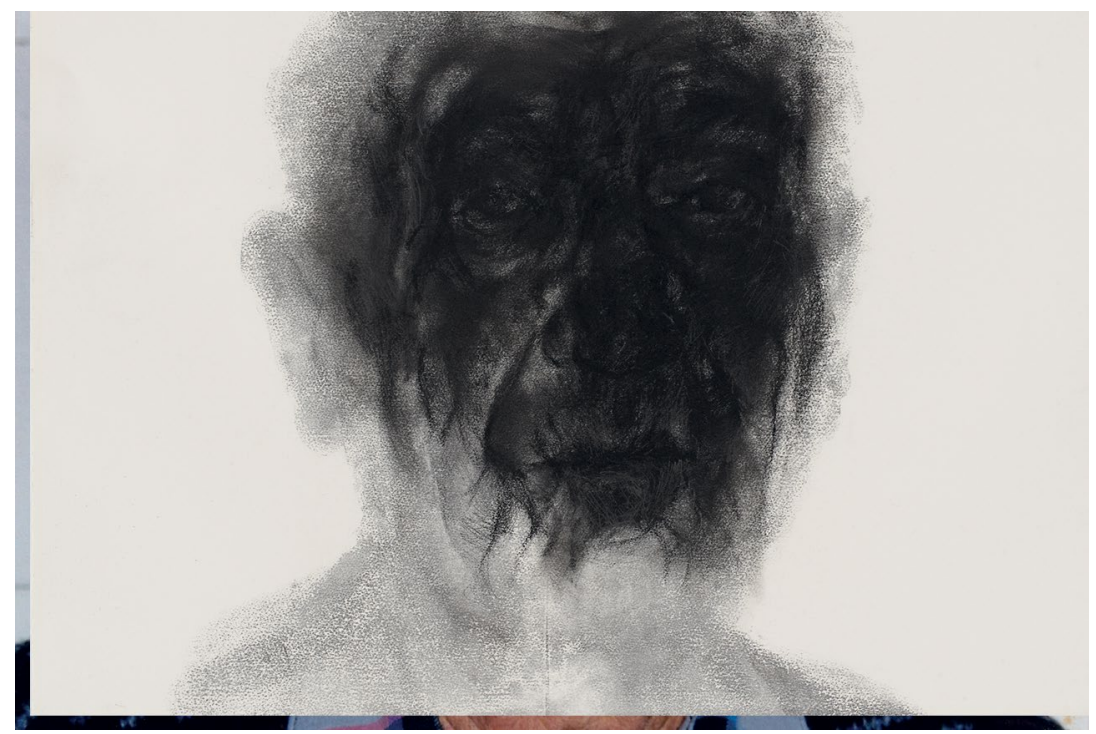

Figure 3.3: Aaron, Gali Weiss, 2000, solvent transfer, charcoal, graphite, $76 \times 56.5 \mathrm{~cm}$.

Source: Courtesy of the artist.

I had been questioning the function of the portrait in my art practice for a number of years, though it is hard to pinpoint the precise time the problematic nature of portraiture first arose for me. Was it with the depictions of my father in the series Aaron (2000) (Figure 3.3)? One of my main concerns then was how to depict the expanse of my father's lifetime in a single image. The more I drew his face at each sitting, and the more details I placed on the paper, the more insignificant the details became. My layered charcoal applications were in effect erasing underlying details, yet I could not stop revisiting those details for they seemed to me in constant change. I decided to 'ground' the image by using a photograph to convey his image stilled, in play with the action of drawing. When I reviewed these images it made sense to me that the viewer's first impression of Aaron was not to be a clear one; though reference to the particular man remained recognisable, details of his features were presented ambiguously. The portrait series of Aaron became one of multiple and fluid images, for there was no one 
total reality or placement that satisfied me - each drawing of Aaron reflected a different subjectivity, whether as a result of my differing interpretations and gestures, or my perception of his different moods.

Perhaps, alternatively, my questioning began with the works of Claire as Naomi (2003), in which I depicted the sitter/subject with reference to the biblical character Naomi. I did not 'dress up' my sitter as the biblical character. My interest was in approaching her as if she were someone else's story. At the same time it was inescapable that I was working with the image of Claire - there was nothing in the image to indicate that this subject was Naomi. The only indication was in the title of the work. I was experimenting with notions of identity in representation, questioning what actually constitutes identity in the image.

My explorations seemed to clearly indicate that I was not satisfied with depicting a fixed image of a person. All my depictions displayed shifts of movement in form and gesture, continuous material layering, at times to the point of erasure. The look of my subject was either uncannily familiar or particular yet anonymous.

By the time I was developing the 2008 body of work presented below, I was recognising these characteristics as purposeful elements of what I termed as diasporic consciousness: elements that arise from common experiences of diaspora. The materials I use in my portraits and in methods of application enact a mobile and ambivalent state of being that is a feature of diasporic consciousness. These transient states of imagery can be viewed as progressions or fragments of a whole. As in the Aaron portraits, my processes and material practice create layered images that are at once marked with gestures and stains, and erased by those marks and stains. Erasure is a significant metaphor for the diasporic experience of loss, with its own traces of marks and stains, where place and time are continuously recreated and relocated in memory and identification.

The subjects of these portraits are interrelated in image and through biological connection. Each image is made up of two referents. One I term the sitter, who has come to my studio to sit for the portrait. The other is drawn from a photograph of a parent or child of the sitter, taken from a time outside the parameters of this project. In selfcritique, I ask how I can use the photograph as a portrayal equal in human presence to the sitter whose presence I have experienced beyond the image. In answer, I remind myself that it is not the essence 
of the human behind the photograph that I am portraying but rather the image of an absent person I know has a significant presence in a relationship they have with the person visiting my studio.

My use of the familial relationships of my subjects in works that incorporate photography, photocopy and drawing proposes a construction not only of a familial subjectivity but of a relational portrait that is simultaneously self and other. The portrait includes my relationship to the sitter and the image of the absent other, while giving heightened attention to the relationship between the two subjects. My drawing attempts to portray particularity, not so much within the facial features or expression of the person depicted as in what the relationship between sitter and imaged absent other instigates within my own artistic practice.

In MotherDaughter (as self-portrait) (2008) (Figure 3.4) each image is made up of my mother's photographed face as an enlarged photocopy transfer together with the observational drawing of parts of my face layered over parts of her face. The areas of watercolour wash surrounding the face have been sandpapered in some places in an attempt to excavate an underlying physical presence.

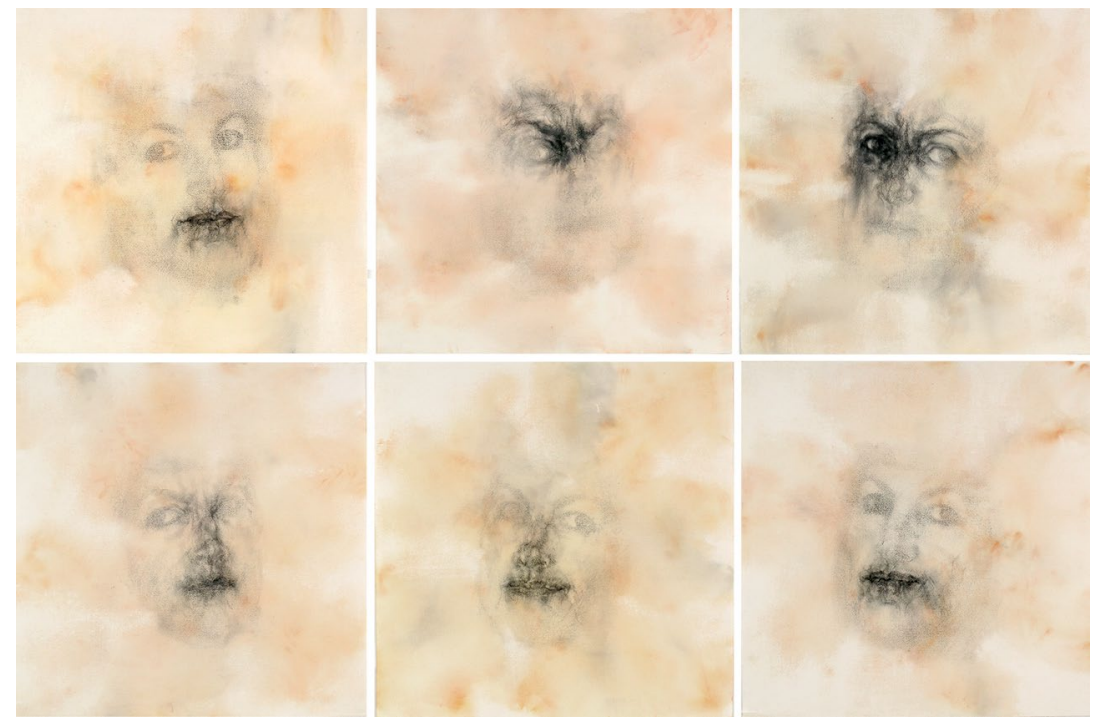

Figure 3.4: MotherDaughter (as self-portrait), Gali Weiss, 2008, watercolour, solvent transfer, charcoal, graphite, $75 \times 75 \mathrm{~cm}$ each of 6 panels.

Source: Courtesy of the artist. 
At first glance, this portrait may be understood as a hybrid or composite of two people. As my portraiture work evolved I began to recognise the complexities of my subjects both as representations and in their referentiality. I had complicated the notion of the portrait's indexical quality by using a doubling of reference, whereby one reference was to the sitter present in my studio and the other to a person related to the sitter, referenced through their depiction in a photograph. The photographic image was photocopied and subsequently transferred onto paper so that reference was made not to the origin of 'person' but to the origin of 'photograph'. Additionally, new subjectivities and relationships were being constructed through the multiple images of the doubling of the subject.

My work draws two subjects into the completion of one portrait that is composed of a number of parts. These parts have in turn been assembled out of variations of repeated images of the two subjects. However, the intent of doubling in my work (the portrait of two people as one) is neither to 'return' to a single referent nor to substitute one being for another. Rather, the oscillation and shifting emphasis of the imagery calls into question the hierarchy of one subject overlaying or displacing the other; the image as well as the subject is at the same time unified and separate, lost and found, present and absent, coming in and out of focus.

Thus while my portraits can be viewed as composites or hybrids, my own experience as maker and viewer simultaneously is of the portrait as a meeting point: of two individual subjects connected by a shared history, heritage and family, and myself as artist/viewer. As both artist and viewer, mark-maker and mark-observer, I am engaging in turn with a relationship that is re-established imaginatively on paper by enacting possibilities for 'meeting' within representation. This 'meeting', in the representation of the subject's facial features, will never bring about a unified whole, but the making and identifying within the process of production - the mark-making and trace - can present the possibility of 'oneness' or completeness. Identifying with the process of production does not mean interpreting the signs of the mark-making but rather re-enacting the processes of materiality that are open to being engaged with imaginatively. In this way, the viewer is invited to enter into that process of possibilities through identification, rather than by recognising an identity. 


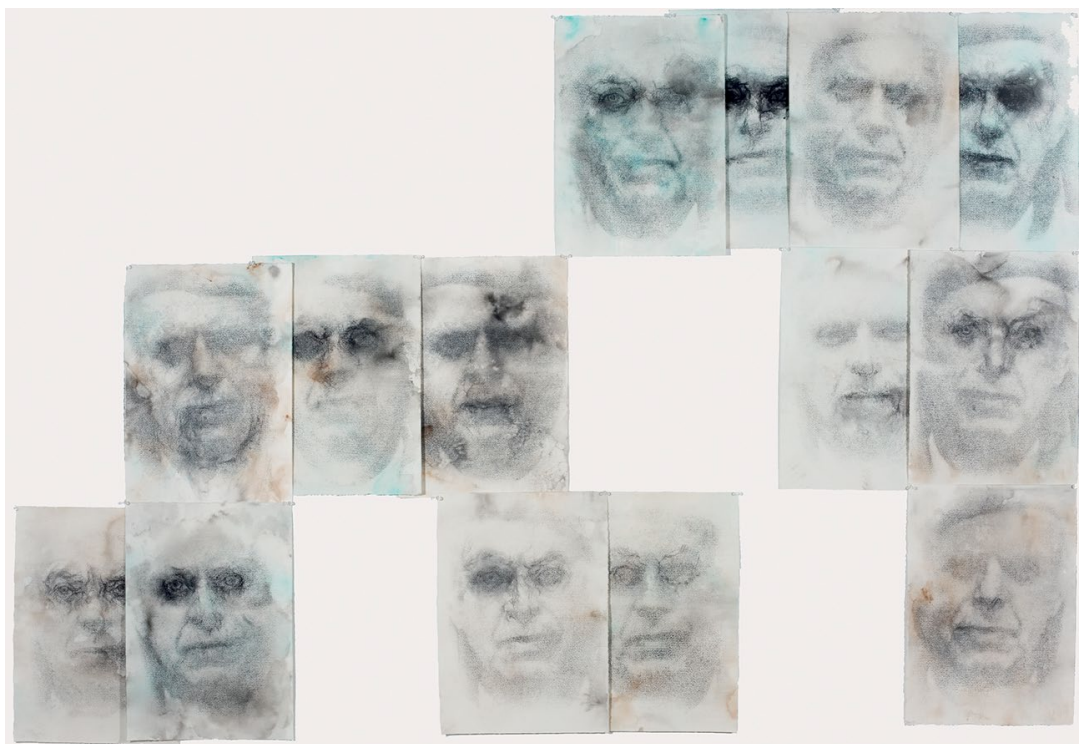

Figure 3.5: FatherDaughter, Gali Weiss, 2008, ink and watercolour wash, solvent transfer, charcoal, graphite, $52.5 \times 37 \mathrm{~cm}$ each of 14 panels.

Source: Courtesy of the artist.

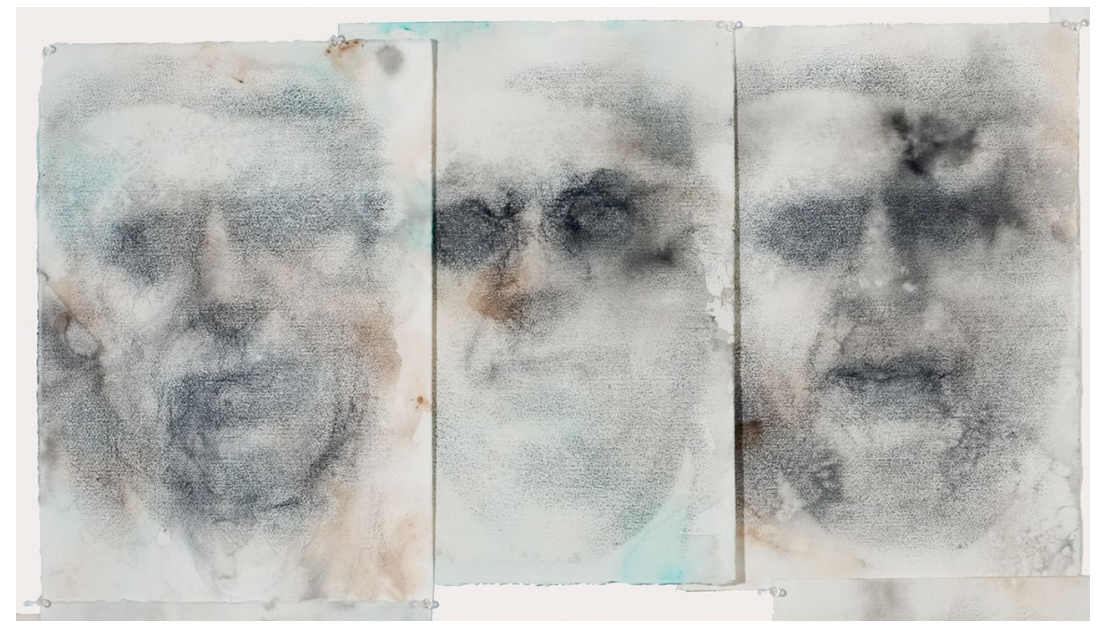

Figure 3.5a: FatherDaughter (detail), Gali Weiss, 2008, ink and watercolour wash, solvent transfer, charcoal, graphite, $52.5 \times 37 \mathrm{~cm}$ each of 14 panels. Source: Courtesy of the artist. 
As with MotherDaughter, FatherDaughter (2008) and MotherSon (2008) (Figures 3.5 and 3.6) present a relational portrait of parent and child, only this time ambivalence extends to displacement in gender. FatherDaughter is a wall installation of 14 panels. The source image of the 'father', the absent subject, is a small photograph in which he poses at a distance from the photographer. The eyes of the subject are in shadow. The marks of drawing are of observational drawing in my studio of the 'daughter', at much the same age as that of the father at the moment of being photographed. While much of the focus is drawn to the eyes, my focus is not limited to the eyes but extends to the whole installation and viewing experience. My focus is multiple, for I am dealing with looking and the look returned, with the spaces between the forms of the individual faces and across as well as within the viewing trajectories of the installation as a whole.

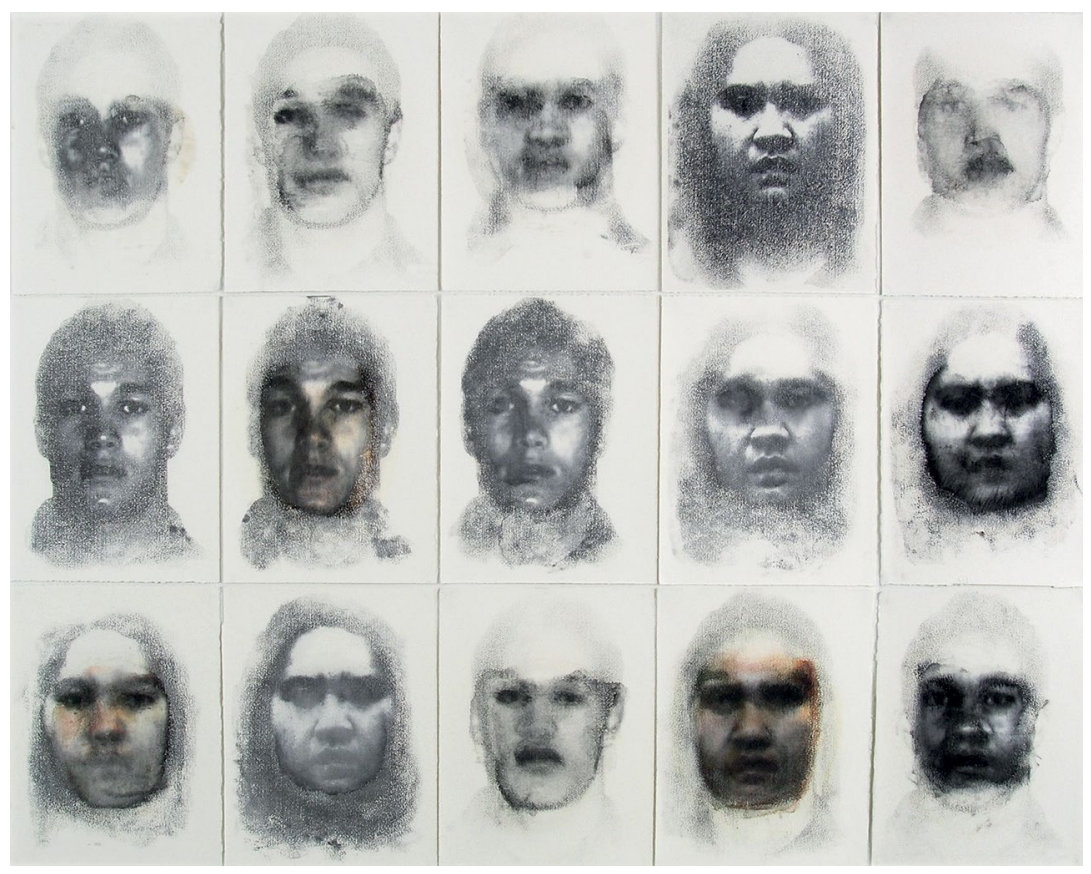

Figure 3.6: MotherSon, Gali Weiss, 2008, solvent transfer, graphite, $37 \times 30 \mathrm{~cm}$ each of 15 panels.

Source: Courtesy of the artist. 
The images in MotherSon (2008) comprise two photographs that have been photocopied and transferred to paper. The original photograph of the 'son' was a small digital print given to me by the 'mother', whom I photographed myself. As in all these portraits, an image of one subject is overlaid with an image of another in various layers, sizes and emphases. Rather than the mark-making of observational drawing, artistic choices regarding material application and chance actions were the crucial interventions in this series. Mine is not only a visual and interpretive relationship with the photograph but also a material relationship via my transferring of the photograph to paper. In undertaking this manipulation of the image and carrying it across in a newly mediated form to establish a relationship with the sitter's image, I attempt to create a space that involves another relationship to the image - that of the viewer.

Materially, the photograph presents me with the stillness of past time captured. The photocopied photograph becomes a tool for thought. It presents me with possibilities for present and future imaging and imagining. The photocopy is transferred onto paper, at times in several layers, with differing manipulations. What is left is the trace of the photograph, which had the trace of the subject, captured at a particular time in a particular place. By using the (photo)copy I am not trying to represent the absent referent, nor the photograph. My intent, rather, is to free up the referent from the context of the photograph into a new imagery in order to interact with him/her as animated presence. One could say that I am setting up a challenge: to diffuse the 'deadness' ${ }^{31}$ of the posed subject and to diffuse the distant 'other', through my material interactions and through the relational positioning of the subject-images. Continual interaction activates this relational presence, not by interacting with the 'pose', which is the face's expression or place, but through the evocation of a dialogue with a human face as subject. The copy mediates between the 'real', stilled subject and myself as artist because the image comes alive as subject in the artistic process of production.

31 Here I use 'dead' in the sense that Roland Barthes gives to the subject position of the photograph, as the person poses for the camera, thereby creating him/herself as other, and thus transforming him/herself into an image: as 'a subject who feels he is becoming an object, I experience a kind of death'. 'I have become Death in person.' Roland Barthes, Camera lucida: Reflections on photography, trans. Richard Howard, New York, Farrar, Straus and Giroux, 1981, p. 14. 
IMAGING IDENTITY
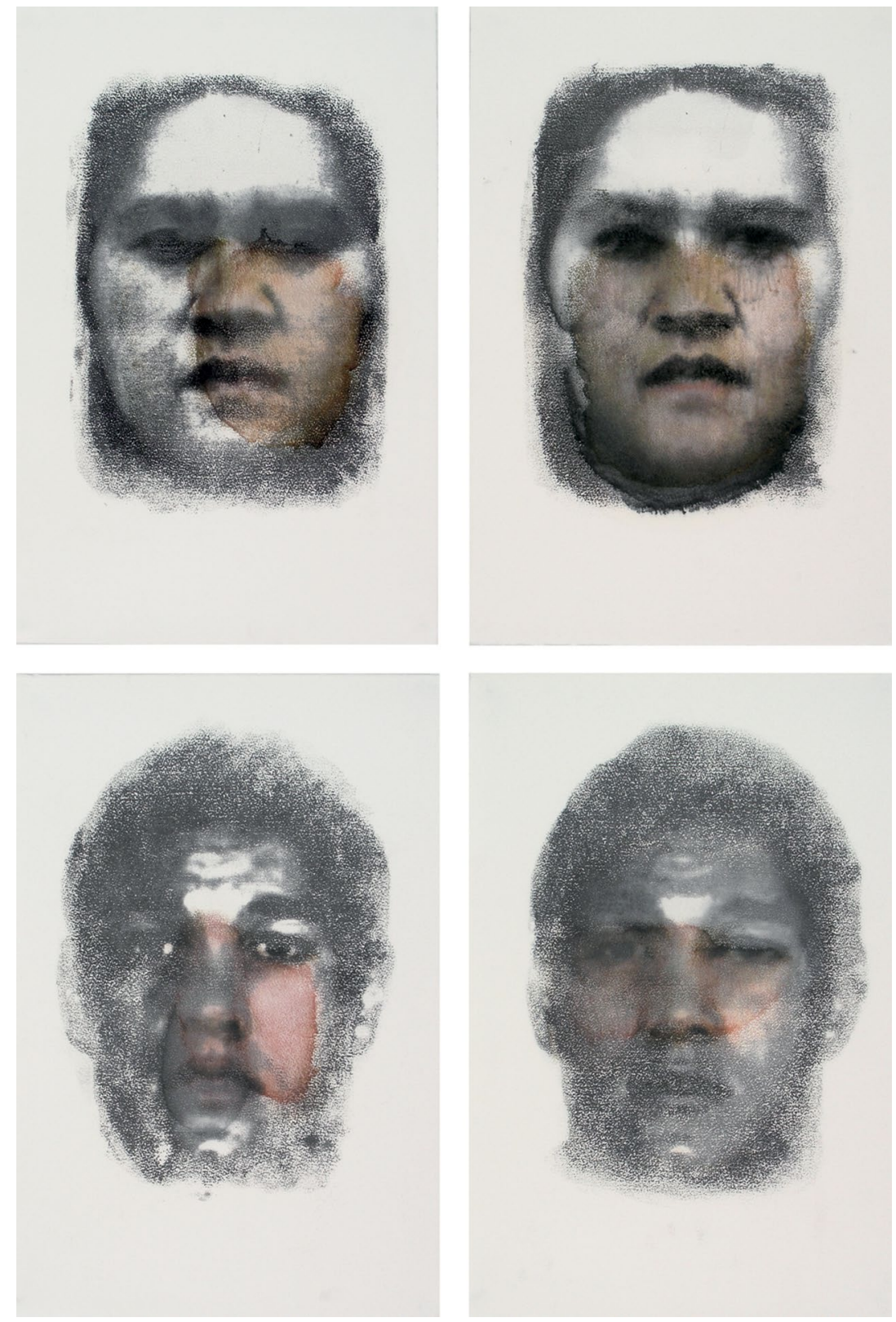

Figure 3.7: MotherSon II, Gali Weiss, 2008, black \& white and colour solvent transfer, $60 \times 40.5 \mathrm{~cm}$ each of four panels.

Source: Courtesy of the artist. 
In MotherSon II (2008) (Figure 3.7), facial expression occurs not through features but through the action and placement of material elements. The border of a stain, for example, affects the expression of a feature of the face. In this way, the portrait shifts from being an iconic object that has a life-presence of its own, or that represents the uniqueness or essence of the person outside it, to function as a site of mediation and negotiation, a site of relationality. In the words of Buck-Morss, my task is 'not to get behind the image surface but to stretch it, enrich it, give it definition, give it time'.$^{32}$ These portraits thus become sites of collective presence and production-in subject, material production and viewing.

\section{Portraiture as culture}

This way of construing the subjectivity of the portrait is at odds with those concerned with the portrayal of the specificity, 'truth' or 'knowledge' of the person portrayed. My primary intention is not to replace such notions of referentiality and 'authenticity' as inform the conventions of portraiture, even though my approach may challenge them. Rather, I have strived to investigate further the productive possibilities of portraiture, 'rethinking' the portrait alongside other current 'rethinkings' of culture, identity and representation.

Avtar Brah suggests that cultures are processes rather than 'reified artefacts'. ${ }^{33}$ Her argument suggests a parallel viewing of portraiture as itself a culture, where the genre can be seen to have a history, a genealogy, an authority and conventions of language and practice. Thus representations that do not comply with the historical, essentialist criteria of portraiture - portraits that, for example, are anonymous yet nevertheless images of persons - need not be viewed as marginal or challenging to the genre, but rather help constitute the genre itself.

The site of portraiture can accommodate works that subscribe to the ideals of unity, homogeneity and pure presence, as well as those that declare the subjective impossibility of such qualities. In this way the space of portraiture can parallel the space of diaspora, or culture at large, where works (and people) that enact a desire for

32 Buck-Morss, 1991, p. 25.

33 Brah, 1996, p. 92. 
unity can co-exist with works (and people) that refute the possibility of fixed and unified positions, but stop short of rejecting tradition. ${ }^{34}$ Hence, portraiture can be understood not so much as a genre within the boundaries of a territory that includes or excludes but rather as a cultural site that contextualises the desire for, in Brah's words, a 'politics of identification'. ${ }^{35}$

By conjoining portraiture and diaspora, I 'think through' notions of identity, subjectivity and representation. My work plays with layered possibilities of subjectivity - with notions of multiplicity, erasure, location and dislocation, of mobility and ambivalence, of self and other, working from a premise of inheritance. Beyond the qualities of transience in the portraits is the figuring of a space in which past and present meet in new formations. The sense of inheritance, of the past that is integral to diasporic consciousness and that includes imaginings of home in place and time, and of futurity, is highlighted in my work through the doubling of subjects and creation of a space of relationality between them.

The completed portraits suggest imprints of memory and postmemory through the duality of subjects but also through the selection of materials and media. The selection and application of materials and processes of production are integral to both the thinking and becoming of diasporic personhood: the photocopy as the copy of a photograph, itself a reproduction, a trace of body, time and place; the adaptive transferring by hand of the photocopy, which at times results in a reductive linear mark, at others a stain alluding to corporeal qualities; the charcoal and graphite gestures of observational drawing that trace the artist's visual trajectory as marks of repetitive exploration, discovery, formation; the paper itself, which lacks demarcation when used as overlapping panels (Figure 3.5) or as a layer and disintegration of a layer between images (Figure 3.8). ${ }^{36}$ The materials are employed not simply as a means of constructing a representation but also as an enactment of that representation, in all its relational aspects.

34 Andrew Benjamin, Art, mimesis and the avant-garde, London and New York, Routledge, 1991, pp. 63-4.

35 Brah, 1996, p. 93.

36 One feature of MotherSon III is the result of the photocopy solvent transfer being applied to the other side of the paper, absorbing into the paper and revealing itself on the viewed side. 


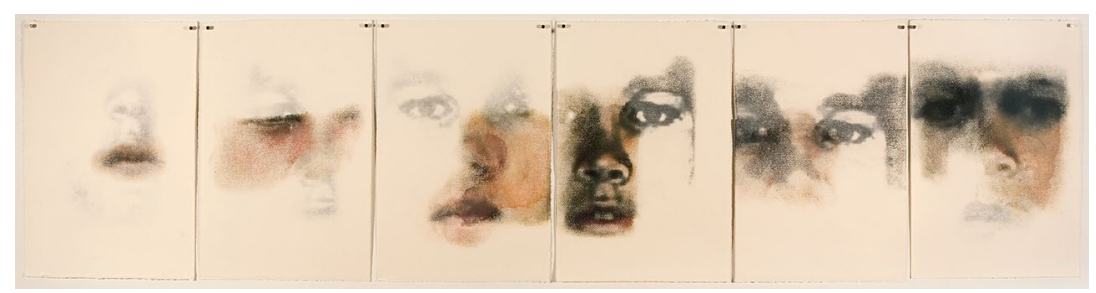

Figure 3.8: MotherSon III, Gali Weiss, 2008, black \& white and colour solvent transfer, 60 x $40.5 \mathrm{~cm}$ each panel.

Source: Courtesy of the artist.

My works attempt to create imaginative possibilities for a dynamic portrayal in a 'still' representation through a relational approach to the portrait as representation and as presence. These portrayals offer simultaneously a collective and an individual representation of personhood and a viewing experience that is participatory - based on identification rather than identity. They contain qualities and address themes that are prevalent within diasporic consciousness and that are commonly experienced as paradoxes of diasporic life: the simultaneity of difference and sameness, location and dislocation, belonging and otherness, particularity and anonymity. Like diasporic space, which encompasses those who leave as well as those who stay and those who return, portraiture can provide a potent space for enacting multiple and transient experiences of presence through which to negotiate the 'home' of authenticity. 
This text is taken from Imaging Identity: Media, memory and portraiture in the digital age, edited by Melinda Hinkson, published 2016 by ANU Press, The Australian National University, Canberra, Australia. 